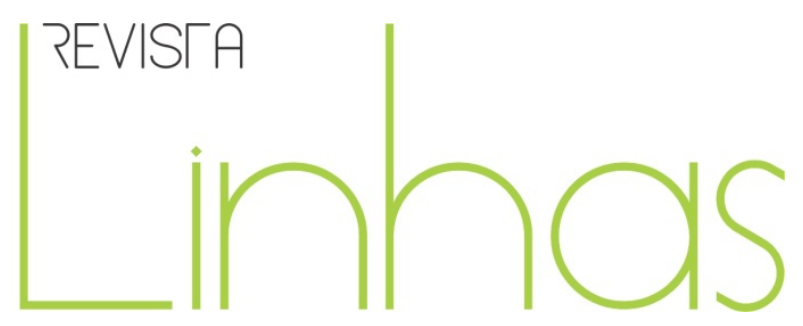

\title{
La razón interpretativa de la educación. Epistemología y nuevas prácticas educativas en la escuela
}

\section{Resumen}

El fundamento teórico de este trabajo se proyecta hacia cuestiones propias de la investigación cualitativa y a una teoría del conocimiento que recoge la dimensión estética de la educación, una concepción constructivista del aprendizaje, una pedagogía interpretativa más que prescriptiva. El método de análisis es, por tanto, de carácter cualitativo basado en una bibliografía reconocida acerca del debate internacional que se lleva a cabo actualmente sobre este tema. La discusión se refiere primero a la crítica de nuestras sólidas tradiciones gnoseológicas. La narración - ésta es nuestra tesis- ofrece una aproximación de tipo hermenéutico al conocimiento que tiende a conjugar diversos enfoques gnoseologicos. En este artículo se proponen hipótesis y ejemplos de un nuevo modelo para educar e instruir en la escuela.

Palabras Claves: Narración; Hermenéutica; Epistemologia; Inovaciòn; Logos; Pathos.

\author{
Anita Gramigna \\ Doutora em Pedagogia pela \\ Universidade de Ferrara - Itália \\ gramy_a@libero.it
}

\begin{abstract}
Para citar este artigo:
GRAMIGNA, Anita. La razón interpretativa de la educación. Epistemología y nuevas prácticas educativas en la escuela. Revista Linhas. Florianópolis, v. 15, n. 29, p. 353-378, jul./dez. 2014.
\end{abstract}

DOI: $10.5965 / 1984723815292014353$

http://dx.doi.org/10.5965/1984723815292014353 


\section{The interpretive reason of education. Epistemology and new teaching practices in school}

\begin{abstract}
The theoretical foundation of this work is projected to issues that pertain to qualitative research and to a theory of knowledge which recovers the aesthetic dimension of education, a constructivist view of learning, a more interpretive than prescriptive pedagogy. The method of analysis is therefore has a qualitative approach, based on a recognized literature about the international debate that is taking place now on this subject. The discussion concerns first the critique of our strong epistemological traditions. The narrative - this is our thesis offers a hermeneutic approach to knowledge that tends to combine various epistemological views. In this article we propose hypotheses and examples of a new model for teaching and instructing in school.
\end{abstract}

Keywords: Narrative; Hermeneutics; Epistemology; Innovation; Logos; Pathos.

\section{A razão interpretativa da educação. Epistemologia e novas práticas educativas na escola}

\section{Resumo}

O fundamento teórico deste trabalho se projeta a questões próprias da investigação qualitativa e a uma teoria do conhecimento que abarca a dimensão estética da educação, uma concepção construtivista da aprendizagem, uma pedagogia interpretativa mais que prescritiva. O método de análise é, portanto, de caráter qualitativo, baseado em uma bibliografia reconhecida acerca do debate internacional que se faz atualmente sobre este tema. A discussão se refere em primeiro lugar à crítica de nossas sólidas tradições gnosiológicas. A narração - esta é a nossa tese - oferece uma abordagem de tipo hermenêutico ao conhecimento que tende a conjugar diversos enfoques gnosiológicos. Neste artigo se propõem hipóteses e exemplos de um novo modelo para educar e instruir na escola.

Palavras-chave: Narração; Hermenêutica; Epistemologia; Inovação; Logos; Pathos. 


\section{Introducción}

La teoría del conocimiento que caracteriza al pensamiento occidental, casi desde sus orígenes, o al menos desde que se les considera como tal, tiene su centro significante en la razón. O sea en aquel sofisticado mecanismo coherente, evidente por sí mismo, consecuente, transparente y autoreferencial que es el intelecto. Es verdad que históricamente se dieron "evidentes desviaciones”: es el caso, por citar el más conocido, del Romanticismo1. El pensamiento romántico trata de construir una lógica del sentimiento que procure la libertad creativa del imaginario. De esa manera los románticos daban valor al papel cognitivo de la imaginación. Pero es verdad también que nuestras tradiciones escolares se consolidaron sobre presupuestos muy diferentes: se privilegió la dimensión racional de la educación en el esfuerzo por alejarse de cualquier margen de error. La lógica llegó a ser instrumento de verdad; y, poco a poco, la verdad se fue sobreponiendo a la realidad.

El intelecto es lógico, ciertamente. Es decir, está libre de turbaciones afectivas, de sugestiones indeterminadas, de aquellas vaguedades de la poesía -por ejemplo- que Platón llegará a negarles valor de conocimiento verdadero ${ }^{2}$. El orden, el rigor, la claridad, la certeza por un lado, y la indeterminación, la ambiguidad, la precariedad por el otro: el logos y el pathos. El conocimiento cierto es aquel que se ciñe a la lógica, así como el comprtamiento de los individuos de la sociedad, cuando es correcto, es siempre racional. Pero ... la realidad nos sugiere muchas excepciones a esta regla. Con frecuencia reaccionamos de manera instintiva y automática a una señal de alarma aún en ausencia del mismo peligro, y sólo en un segundo tiempo "reconstruimos" la explicación de nuestra reacción conforme al principio causal, lógico, racional..., o bien imaginando haber percibido un riesgo. El motivo depende del hecho que nuestro cerebro es llevado a narrar historias -a reconstruir secuencias de eventos- sobre la base de inferencias causales. Desde Platón", aunque con algunas "desviaciones" sustanciales, lo emocional se

\footnotetext{
${ }^{1}$ Cfr. Por citar sólo entre los ejemplos más notables: Novalis (pseudónimo de Friedrich von Hardenberg) Opera filosófica, 2 vol. Editado por F. Desideri y G. Moretti, Torino, Einaudi, 1993; y F. Schiller, Sulla poesia ingenua e sentimentale, tr. it., E. Franzini e W. Scotti, Milano, Studio Editoriale, 1986.

${ }^{2}$ Cfr. Platón, La República, trad. De Antonio Gómez Robledo, UNAM, México, 1971.

${ }^{3}$ En la tradición presocrática el sentimiento, en cuanto máxima expresión de la sensibilidad y de lo intuido,
} 
contrapone a lo racional, con toda la ventaja para este último. Así, se ha venido profundizando aquella censura antigua que, poco a poco, ha llegado a ser motivo y estructura de los comportamientos humanos, estableciéndose en el yo, en lo social, en la cultura, en el conflicto entre logos y pathos. Un conflicto que ha condicionado nuestro sistema simbólico y que ha marcado los mecanismos cognitivos. Esta separación entre lo afectivo y lo lógico se percibe como "ontológica", o como estructural, en el proceso de construcción del conocimiento, y ha llevado a subestimar el valor gnoseológico de lo emocional, de lo estético, de lo lúdico y de lo onírico. La educación, como el arte, se expresa en hechos que pueden ser descritos y analizados sólo a condición de servirse sucesivamente de diferentes criterios narrativos, de aproximaciones cognitivas, creativas y flexibles y de instrumentos lógicos y abiertos.

Poesías, cuentos, fábulas y rimas infantiles afinan las necesidades del lector y las hacen más complejas porque contienen mecanismos que involucran su personalidad integral. Lo lanzan al universo lúdico del "como si”, evocan una polisemia de mensajes y valores que destaca, sean los aspectos intelectules, sean aquellos emocionales y afectivos, sin solución de continuidad.

\section{El pensamiento narrativo}

Todo conocimiento, incluido el que llamamos "por imágenes", y el verbal y abstracto, implica una cierta habilidad para crear mapas dinámicos de lo que acontece en nuestro organismo, de lo que sucede fuera, de las relaciones que empalman estos acontecimientos. Más aún, presupone una habilidad notable para moverse con creatividad entre tales mapas, establecer relaciones y recorridos de significación. En una palabra, se basa en la disposición de nuestro pensamiento para narrar. Quizás nuestro cerebro desde el inicio de su larga evolución ha narrado historias, o bien ha registrado lo que acontecía a modo de mapas. En este sentido, la narración, desde el punto de vista de la evolución, habría precedido a su propia evolución y no al contrario como se ha creído.

no se separa todavía del pensamiento, y tiene, en consecuencia, un valor cognitivo. Con el Cristianismo arcaico, el sentimiento se identifica con la fe y mediante la elevación mística alcanza una forma superior de conocimiento. Cfr. S. Vegetti Finzi, Storia delle passioni, Bari, Laterza, 1995. 
Si esto es aceptable, las consecuencias en el plano cognitivo son enormes, como ya lo mostró, entre otros, Taylor ${ }^{4}$. Este estudioso sostiene que la narración es la forma constitutiva de la educación y su principio epistemológico.

En esta línea de reflexiones ubicamos también el pensamiento de Bruner: "Nosotros transferimos siempre nuestros intentos de comprensión científica de forma narrativa, o, por decirlo así, de heurística narrativa" ${ }^{5}$. De hecho, continúa el autor, el “narrar" es patrimonio universal del género humano, como el hablar. Y de la narración nace aquel proceso relacional, multifactorial y multidireccional, que conduce al aprendizaje. El principio narrativo del que habla Bruner se refiere al papel fundamental del descubrimiento autónomo; un descubrimiento que puede nacer de la posibilidad de realizar los viajes que sugiere la narración, pero también de elaborar narraciones autónomas, sobre la onda emotiva de aquellas sugestiones.

Por esto, el autor afirma significativamente: "dediquemos un enorme esfuerzo pedagógico a la enseñanza de los métodos de la ciencia y del pensamiento racional: cuáles son los requisitos de la verificación, qué constituye una contradicción, cómo transformar afirmaciones simples en proposiciones verificables, etcétera. Porque estos son los métodos para crear una realidad según la ciencia. Sin embargo, vivimos la mayor parte de nuestra vida en un mundo construido según las reglas y medidas de la narrativa. Ciertamente la educación podría favorecer más de lo que ahora lo hace el surgimiento de la sensibilidad metacognitiva, necesaria para construir la realidad narrativa con toda su contradictoriedad" ${ }^{6}$.

La antigua separación entre logos y pathos puede ser un incentivo a favor del aprendizaje sólo si la utilizamos didácticamente en sentido instrumental, o sea metodológico e hipotético. Cuando tal separación se convierte en la estructura y el motivo más íntimo del comportamiento en todos los niveles del quehacer humano, se convierte en esquizofrenia. La separación artificial de lo racional y lo sentimental, trae,

\footnotetext{
${ }^{4}$ D. Taylor, Le storie ci prendono per mano, Piacenza, Frassinelli, 1999.

${ }^{5}$ J. Bruner, La cultura dell'educazione, Milano, Feltrinelli, 1997, tit. orig. The culture of education, Harvard University Press, 1996.., p. 138. cfr. también: J. Bruner, La costruzione narrativa della "realtà" in Ammanniti M., Stern D.N. (a cura di), Rappresentazioni e narrazioni, Bari, Laterza; J. Bruner: La fabbrica delle storie: diritto, letteratura, vita. Bari, Laterza 2002.

${ }^{6}$ Idem, pp. $163 / 164$.
} 
por una parte, la mitificación de lo mental, y por otra, llega hasta la negación de lo afectivo. Por eso, la pérdida de consciencia respecto del pathos que, no teniendo legitimidad gnoseológica e intelectual, permanece en el reino de lo irracional, de lo no comprensible y de lo no domesticado, es decir, de lo dionisíaco, para utilizar la conocida distinción nietzscheana.

Buena parte del comportamiento de educadores y docentes se ha modelado, más o menos involuntariamente, sobre este esquema abstracto que ha sido propuesto a los alumnos a partir de sus primeros pasos en la aventura escolar. El costo de esta oposición es muy alto porque se ha anclado en el yo, en lo social, en la educación, un permanente conflicto a través de la negación del valor cognitivo de las pasiones. La actividad intelectual, en sus diferentes niveles, está densamente poblada de tensiones afectivas. De hecho, las emociones -sean o no conscientes- ejercen un efecto prolongado en el tiempo si se cambian en sentimiento y se anclan en la conciencia. Creemos que sólo con una clara percepción de un sentimiento del yo, el sujeto llegará a la conciencia de los sentimientos que experimenta. En este sentido, y citando una bella expresión de Antonio Damasio, podemos afirmar que el sentimiento es la experiencia mental de las emociones ${ }^{7}$. Según Damasio, la conciencia amplifica el impacto de los sentimientos y emociones en la mente. Más aún, sostiene que es "nuestra primera autorización para conocer" 8 y que por tanto nos "ayuda a perfeccionar el arte de la vida" 9 . En efecto, es la conciencia lo que hace conocido para el sujeto el sentimiento de una emoción.

La educación debe recomponerse en el encuentro-integración entre dos momentos: el racional y el sentimental, que representan sólo una separación de tipo metodológico, lingüístico e instrumental y no ontológico, del proceso del conocimiento y de la educación. En la narración -en su transfiguración y recomposición metafórica de la realidad- se ha restablecido ese precioso equilibrio. Aquí el lenguaje estético se ha fusionado con el del pensamiento. Quizás, aquí concretamente, podemos volver a trazar algunos elementos para una didáctica diferente, porque la narración puede otorgarnos

\footnotetext{
${ }^{7}$ A. R. Damasio, Emozione conoscenza, Milano, Adelphi, 2003, p. 59.

${ }^{8}$ A. R. Damasio (1999), Emozione e coscienza, Milano, Adelphi, 2000; tr. it. The Feeling of What Happens. Body and Emotion in the Making of Consciusness, p. 17.

${ }^{9}$ Idem, p. 18.
} 
una aproximación global al conocimiento, lo que, dadas nuestras costumbres escolares, implica al mismo tiempo la participación en las emociones, los sentimientos, las sugestiones de otros, pero también implica una toma de conciencia intelectual y cultural.

Sumergirse en una narración, en una novela, en una poesía, en un fábula ... nos permite respirar aquel clima, sentir aquella atmósfera, imaginar -intuir- un universo lejano, pero también identificar los lenguajes, los giros estilísticos, los contenidos culturales, la visión del mundo. La aventura, la magia, lo lúdico, elementos constitutivos de la literatura, nos atraen porque contienen un juego emocional que es también intelectual y porque nos proyectan, con frecuencia sin darnos cuenta, dentro de comportamientos hermenéuticos que, aislados, pueden ayudarnos en la enseñanza y en el aprendizaje a recoger las oportunidades cognitivas de una mente que se nutre también de afectos. La "fusión" con la narración, la fábula, la poesía ... puede llevar al joven a comprender por empatía, pero al mismo tiempo también, mediante una aproximación crítica y consciente, la experiencia de una propia producción artística de la realidad, o sea, de una metáfora-transfiguración en base al modelo de la belleza.

Por esto es un lenguaje, el de la narración, que se refiere al logos pero también al pathos, que se inserta en el análisis y en la crítica, pero también que alude a diversas aproximaciones cognitivas. El estilo cognitivo que la narración trae a cuento presupone una actitud hermenéutica que se apoya en la intuición, que requiere de sugestiones, que suscita emociones, que hace soñar. Es la evasión de lo contingente lo que provoca la inmersión en el juego de la aventura, fascinación y encanto. Es a través de esta forma de "participación” que se da aquel intercambio entre lógica e imaginación, entre análisis crítico y tensión afectiva, lo cual constituye, así lo sostenemos, la contribución más preciosa que ofrece la literatura a los procesos de crecimiento de un niño. La armonía recuperada entre mente y afectos.

Nuestra propuesta educativa consiste, por tanto, en una aproximación cognitiva de carácter hermenéutico que vuelva a trazar y reconstruya las relaciones entre emotividad, fantasía, creatividad y pensamiento formal. Se trata de establecer nuevas prácticas educativas de apertura a la vertiente estética del conocimiento; de cambiar la aproximación puramente lógica en lógica-participativa, es decir, apoyarse también en la 
participación, la interpretación y la intuición. Adentrarse en los meandros del pensamiento literario ayuda evidentemente a dar forma narrativa a los conocimientos, las experiencias, a lo vivido... a hacer más inteligible los lugares escondidos de la personalidad, los rasgos importantes de su estructura, a lograr que el joven narre su propia historia, a construir su identidad.

Por este motivo es fundamental para cada uno de nosotros, de cualquier edad, adquirir la capacidad de crear y comprender narraciones, cultivar una sensibilidad narrativa que llegue a ser un instrumento intelectual más que cultural. Lo narrativo elabora imágenes del conocimiento, organiza sus recorridos y estructura su lógica. Pero, a diferencia de lo que sucede con frecuencia en los códices, en los modelos, en los lenguajes del conocimiento al que se considera como "objetivo", lo narrativo está abierto a las contaminaciones linguísticas, a los enfrentamientos epistemológicos, a las más variadas y flexibles aproximaciones cognitivas.

\section{Epistemología de la narración}

La narración es una forma primigenia de organización del conocimiento como lo demuestran los mitos y las fábulas. La narración es un viaje cognitivo dentro de una época, un punto de vista o dentro de nosotros, o mejor aún, dentro de todas estas cosas contemporáneamente y fuera de ellas. O sea, dentro de una forma de pensar que nos pertenece y que el cuento nos vuelve a proponer de forma meditada y refinada. Un pensamiento que es, por tanto, al mismo tiempo natural en cuanto asimilado a nuestra forma de entender al mundo y a nosotros mismos, y artificial porque se sirve del arte de la escritura.

Sostenemos que la rarración es un modo de pensar porque nos sugiere las estructuras para interpretar mejor nuestros conflictos existenciales, para organizar mejor nuestro conocimiento, y para crear y determinar en él diversos campos. La aproximación por parte del lector frente a esta forma de conocimiento es, una vez más, interpretativa. A la interpretación del autor se enlaza, y en parte se sobrepone, la del lector que, a su modo, 
con su participación, hace más compleja la historia narrada. La racionalidad del mundo parece así menos unívoca y más dudosa, sujeta constantemente a revisiones y nuevas sistematizaciones. Creemos que es propio de la forma narrativa ofrecer al lector una nueva visión de cuanto pertenece al sentido común, quizás porque, como lo sugiere Foucault ${ }^{10}$, la narración pertenece a la arqueología del saber. Pero, para recoger toda la belleza de un cuento, es necesario ayudar a los niños a estar disponibles, emotivamente antes que intelectualmente, a ser cómplices del libro y de su autor, a dejarse llevar por el ritmo narrativo, a visitar contextos desconocidos, a encontrar palabras nuevas, a desquiciar las costumbres de nuestros mismos prejuicios.

Por esto pensamos que la experiencia de la belleza, del encanto, de la curiosidad, debe venir primero de los ejercicios de separación (puntos de vista, palabras clave...), de análisis gramatical, y de exégesis de los textos literarios. El encuentro con la literatura nos estimula a participar en las sugestiones y sentimientos que la obra deja entrever, pero al mismo tiempo implica una toma de conciencia intelectual y cultural del pensamieno que la sostiene, del fundamento crítico, de la propuesta. No es fácil ayudar a los sujetos a elaborar sus instrumentos de lectura y de orientación que los acompañen en el camino que es la búsqueda del significado profundo. El significado profundo que puede asumir nuestra vida no se puede enseñar, no existe un método científico para encontrarlo, o una receta para elaborarlo, ni mucho menos un manual de instrucciones para edificarlo. Parece que las palabras de la ciencia -incluída la llamada humanística- son insuficientes. Los márgenes semánticos de los términos filosóficos parecen, de pronto, muy angostos. Es quizás por esto que Platón, en su República, pensaba que la mente de los gobernantes debería estar educada con la lectura de mitos. Porque las palabras de la ciencia no bastan.Tenemos necesidad de la metáfora. Es la metáfora la única que puede ayudarnos a construir nuestros propios instrumentos de lectura y de orientación para enfrentar la incertidumbre que el mundo, y nuestra presencia en él, generan en nosotros. ¿Por qué la metáfora? Porque nos lleva a una realidad donde siempre se esfuma su finitud en cualquier otra cosa que se le asemeja, a la que alude, evoca, y por esto habla a cada uno

\footnotetext{
${ }^{10}$ M. Foucault, L'Archéologie du savoir, Paris, Gallimard, 1969; (tr. it., L'archeologia del sapere, Milano, Rizzoli, 1971).
} 
de nosotros, individualmente, porque cada uno de nosotros persigue su propio significado existencial. Así, el lenguaje metafórico es inmanente al proceso formativo, trans-formativo. La narración nos educa en el sentido profundo de las cosas sin tonos didácticos porque nos propone un juego de relaciones entre eventos, situaciones y entes que se ofrecen a nuestro pensamiento como metáforas. Cada metáfora, como cada imagen literaria -sugiere Alessandro Bosi- ${ }^{11}$ contiene en su códice genético la totalidad de la historia -las historias- que cada uno de nosotros ha esbozado y que esbozará en la fábula de una narración existencial. En este juego multi-direccional y multi-factorial, representa un papel magistral lo imprevisto que irrumpe en la escena para revolver los planos y que prepara para nuevas comprensiones del mundo, es decir, emociona y espanta, justo como las fábulas o los cuentos. Organizar y proyectar es cuanto compete a la educación, pero la educación va más allá: corteja a la vida en su fluir y se enamora de lo inédito porque es lo nuevo lo que deja huella, lo que marca el punto del cambio. Así, pensamos, la educación tiene un corazón narrativo porque la metáfora, de la que se sirve la narración, es una estructura estética. La metáfora expresa aquel excedente de significado irreductible que escapa a las palabras, a los esquemas, a los modelos, a los métodos y a las recetas. Se trata de una semántica que podemos intuir sólo emocionalmente y que tiene un alto valor educativo porque nos ayuda a comprender nuestro puesto en el mundo.

La ambiguidad, o bien la legitimidad de diversas interpretaciones igualmente plausibles, es un rasgo característico de la metáfora y de cualquier experiencia estética. Tal legitimidad permite a cada uno buscar su propio sentido existencial, precisar posibles claves de lectura de los nodos problemáticos que nos acompañan durante la vida, interpretar el mundo, sus símbolos, sus maravillas y responder a sus imprevistos. Esta ambivalencia nos ayuda a introducir nuevas imágenes en contextos habituales y viceversa. Nos educa para utilizar creativamente los símbolos y las conexiones de significado a las que se puede aludir. Tales operaciones son de gran interés desde el punto de vista cognitivo y mucho tienen que ver con la generación del imaginario y de manera más general, con la formación. En la aventura como en el arte, las emociones

\footnotetext{
${ }^{11}$ Bosi A., (a cura di), Identità e narrazione, Milano, Unicopli, 2003.
} 
desarrollan una fundamental función cognitiva ${ }^{12}$. La narración nos aclara la naturaleza dinámica de la realidad y su relación de desvelar-ocultar, que la metáfora siempre anticipa y exalta y que se refiere a las dinámicas existenciales. En consecuencia, posee un papel propiamente cognoscitivo y se refiere a la formación.

Creemos que la narración favorece el acceso a la profundidad de los significados, a sus consecuencias existenciales, a la trama ética que sostiene nuestras relaciones. Creemos que esto sea verdad sobre todo para los niños porque la narración, más fácilmente que la explicación, puede adaptarse a las distintas etapas de desarrollo infantil, al sentido lúdico y estético que anima la mente infantil. El niño -y en el fondo también nosotros- requiere interpretar las posibles respuestas a sus preguntas mediante relatos que susciten la curiosidad, que diviertan, que estimulen la imaginación, que aclaren sus emociones, que ofrezcan posibles interpretaciones a sus ansias y a sus necesidades. Los personajes de los cuentos, fábulas y novelas son típicos, ejemplifican algunas características notables que nos permiten identificarnos con el personaje que se enfrenta a un problema y lo vence. Los niños son mucho más complicados que los protagonistas con los que se identifican, pero justo por esto, los tipos literarios ofrecen claves de interpretación de los contextos y situaciones problemáticas, de las ansias que generan, de los conflictos y de los dilemas que agitan la vida interna de cada uno de nosotros. Lo típico, tanto de los personajes como de las situaciones, no permite forma alguna de ambivalencia y sugiere, por tanto, respuestas, interpretaciones, orientaciones, justo porque representan extremos de conductas y de eventos ${ }^{13}$. Es éste el interés que la narrativa suscita y al mismo tiempo su mecanismo educativo. Es aquí también donde el niño y el joven comienzan a comprender cómo enfrentar la dependencia que los ata a una afectividad que debe evolucionar con su crecimiento.

\footnotetext{
${ }^{12}$ Cfr. a questo proposito anche L. Maffei e A. Fiorentini, Arte e cervello, Bologna, Zanichelli, 1995; A. Pinotti, Estetica ed Empatia, Milano, Guerrini e Associati, 1997.

${ }^{13} \mathrm{Cfr}$., A. Escolano Benito e A. Gramigna, Formazione e interpretazione, Milano, Angeli, 2004.
} 


\section{La lógica narrativa de la educación}

La lógica narrativa de la educación se vincula con la emoción, la belleza, la aventura, y, al mismo tempo, con la semántica profunda y metaformativa, en el sentido que favorece el desarrollo de la personalidad y construye prácticas de autohermenéusis. En una palabra, ayuda a los sujetos que están en desarrollo a conocerse mejor. Se trata de una aventura educativa extraña, desacralizante, "encantadora”, un poco herética. Herética respecto al orden constituido que reina entre los saberes formalizados de la escuela; herética porque utiliza un registro diferente del que habitualmente se usa en la práctica escolar, porque el códice que adopta es más evocativo que explicativo. Más aún, porque persigue una experiencia que es ante todo belleza, y que después, sólo en un segundo tiempo, puede devenir conocimiento gracias a la labor formalizadora de la escuela y al hecho de constituirse en un orden gnoseológico.

La escuela propone compromiso, en el mejor de los casos compromiso gozoso, pero siempre con un fin, nunca gratuito, nunca un fin por sí mismo o autolegitimante como sucede con la dulce fatiga del juego. Si el paradigma de la enseñanza escolar se realiza en los procesos, en los métodos y en los contenidos del conocimiento, el de la literatura, aún en su función escolar, tiende principalmente al sentido de lo bello. Es sobre todo forma. Contenidos y métodos se pliegan y disciplinan según las exigencias estéticas. Esto no necesariamente sucede en la práctica de la enseñanza. Por esto los cuentos, las fábulas, las rimas infantiles, las poesías, nos proyectan inexorablemente hacia un orden que utiliza diversas coordinadas, a veces ciertamente invertidas respecto a las que dominan en el lenguaje formalizado en la escuela. Son "visiones" que ayudan al lectorescucha a obtener el sentido de la complejidad de lo real, de sus infinitas interpretaciones-manipulaciones, del uso diferente de palabras, códigos, estrategias. Su dimensión "fantástica” y "maravillosa”, además, resulta muy rica en los textos para los más pequeños y favorece su percepción prospectiva de la realidad. Se trata de una percepción que clarifica el mundo, sea como interioridad o bien como exterioridad, en la medida en que el niño aprende a reconocer y a gobernar los inquietantes fantasmas y los arrebatos de felicidad. 
Estamos convencidos que el sentido de lo maravilloso representa un arma potente contra el miedo de crecer, para los niños, y el miedo de cambiar, para los adultos. Lo maravilloso habla a cada uno de nosotros en una lengua diferente, porque nuestros mecanismos de identificación apoyan nuestra especificidad y peculiaridad que nos contradistingue. El significado de lo maravilloso, de hecho, puede leerse en diferentes niveles, como sucede en la naturaleza metafórica de las artes y de las narrativas particulares. La emoción de la belleza matiza la sensación en la adhesión, en el consenso, en la comparación de las cosas. La belleza de la narración, las imágenes que nos sugiere, las visiones que evoca, nos ofrecen claves de lectura de las dinámicas emotivas, sentimentales, oníricas a través de las cuales nosotros, y sobre todo los niños, leen una parte del mundo que los rodea. Los nodos esenciales se exteriorizan, se hacen más fáciles de comprender y aparecen menos angustiantes. Frente a la emoción estética de lo bello, de lo maravilloso, de lo fascinante, nuestra persona aparece a veces como subyugada, los sentidos alerta, la atención capturada en la percepción-intuición de aquella armonía cuyo secreto se representa. Se trata casi de un reconocimiento, un recuerdo de lo que desde siempre deseamos con todo nuestro ser. Es la razón que se deja invadir, callada, por la emoción, y que pone en el pensamiento sus contenidos. Es racionalidad que se torna poética. Y nos hace crecer. Deslumbrada por una mirada onírica sobre el mundo, la razón narrativa reconoce los fragmentos esenciales del sentido. Esta adhesión emocional se asemeja mucho a la empatía, a los más altos niveles de intensidad, captura, en su plenitud, a nuestro ser que jamás como ahora se siente libre de vibrar a través de esa sensación y de comunicarse con quien está a su lado. De aquí la importancia de la narración en alta voz, de la recitación de cuentos, fábulas o breves piezas literarias.

La belleza de las imágenes literarias, del ritmo narrativo, de la musicalidad de las palabras, de las metáforas, se da con un sentimiento de don, el placer que evoca es gratuito porque no tiene objeto alguno. Somos capturados en nuestra atención y, al mismo tiempo, en esta experiencia de identificación; nos sentimos infinitamente libres. Vibramos con una alegría que nace de un fin privado de objeto. La experiencia estética que la literatura nos sugiere nos toca propiamente en el significado más profundo de nuestra humanidad, que es desde luego la libertad, que es la esencia de la ética. Estas son 
las dinámicas calladas de la semántica narrativa de la educación. La narrativa ayuda a los jóvenes -y también a los adultos- a interpretar sus propias desilusiones narcisistas, las dependencias afectivas, las rivalidades amistosas, el egocentrismo, la agresividad antisocial porque aclara los mecanismos, las situaciones, los riesgos. Un fin de la pedagogía narrativa es ciertamente el de construir elementos metafóricos para la iterpretación de tales dinamismos, ampliando los horizontes imaginativos de los niños y los adultos. Más aún, en la educación la narratividad cumple otra importante tarea: proporciona material literario para estructurar fantasías, sueños a ojos abiertos, creatividad. El sentido narrativo de la educción ofrece principios metodológicos, es decir, estilos cognitivos estéticos y materiales -imágenes y metáforas- para elaborar nuevos escenarios de lo real, porque siempre alcanzan contenidos existenciales, nodos problemáticos que son intrínsecos a la aventura humana, y por esto, universales.

Por lo demás, que la hermenéutica sea el corazón del mecanismo formativo es evidente por el hecho básico que educar significa, primero, ayudar a interpretar el mundo, o sea, formar al sujeto para su comprensión. La prospectiva hermenútica resulta coherente con la aproximación narrativa, en tanto que la interpretación requiere recoger en las partes una coherencia significante, aunque provisoria o incompleta. El saber recoger-construir tal coherencia implica, por su parte, el favorecer las conexiones en planos diferentes de elementos que, a primera vista, pueden aparecer irreconciliables o lejanos, o que como tales, constituyen obstáculos a la visión de conjunto. La dificultad para establecer relaciones significantes entre los elementos y niveles de lectura genera esa confusión, esa dificultad para orientarse, para comprender e interpretar, que es típica de nuestra sociedad compleja ${ }^{14}$. Por este motivo podemos contar a la hermenéutica entre los paradigmas de una pedagogía de la complejidad a partir del reconocimiento del valor gnoseológico de la narración.

\footnotetext{
${ }^{14} \mathrm{Cfr}$. N. Luhmann, Struttura della società e semantica, Bari, Laterza, 1983, tit. orig. Gesellschaftsstruktur und Semantik, Suhrkamp, Frankfurt am Main 1980; N. Luhmann, Sistemi sociali. Fondamenti di una teoria generale, Bologna, II Mulino, 1990, tit. orig. Soziale Systeme. Grundriss einer allgemeinen Theorie, Suhrkamp, Frankfurt am Main 1984.
} 


\section{Desestructurar el logos de la escuela}

Creemos que ante esta tentativa desestructurante del logos escolar, disciplinar, pueda surgir una propuesta formativa sobre el lenguaje narrativo del saber educativo y sobre su papel en la hermenéutica educativa. En el fondo de esta teoría y de acuerdo a las reflexiones acerca de la semántica narrativa de la educación, nos preguntamos qué pensamiento puede ayudarnos "desde fuera" 15 a precisar los puntos de ruptura de la pedagogía, a cuestionar nuestras certezas acerca del saber que enciende esta disciplina, a generar diferencias que producen sentido y libertad. Esta será nuestra tendencia y nuestra propuesta, a partir de una semántica narrativa de la educación.

La narración enseña, y al mismo tiempo juega con nuestro pensamiento. Lo hace construyendo tanto nexos de significación entre nuestra experiencia existencial y el mundo, como criterios de lectura de lo real, y los conocimientos organizados de acuerdo a sus elementos cognitivos. En lo lúdico está el mecanismo educativo de la narración. En ello el niño expresa una suerte de tensión, de energía, de deseo que no persigue ningún otro fin que la creación de diferentes imágenes y/o formas del yo ${ }^{16}$. La literatura es una vía maestra en la formación de tales imágenes. Se trata de un juego que sugiere metáforas de la realidad: imitaciones. En esa mímesis, cualquier sujeto que juega encuentra satisfacción, placer, emoción, y también el logos, porque la mímesis es un carácter fundamental de lo simbólico. “El juego de ficción (...) produce una satisfacción en el plano imaginario que puede sustituir al plano real. El haber simulado se encuentra a la mitad de camino entre el tener y el no tener: y aún así produce un efecto consolador" ${ }^{17}$. Más aún, el imaginario puede representar para el educador una suerte de laboratorio experimental: En el nivel de lo imaginario -escribe Paola Santagostino- se pueden inventar, probar y reprobar infinitos caminos, siguiéndolos hasta sus últimas consecuencias en la búsqueda

\footnotetext{
${ }^{15}$ Acerca del uso de esta expresión, cfr. M. Foucault, Les mots et les choses, Paris, Gallimard, 1966, trad. it., di E. Panaitescu, Le parole e le cose, Milano, Rizzoli, 1967.

${ }^{16}$ Cfr., Escolano Benito A., La memoria y el deseo. Cultura de la escuela y educacion deseada, Valencia, Tirant lo Blanch, 2002.

${ }^{17}$ M. Gagliardi, Le stelle nascoste. Mappa dell'immaginario infantile, Venezia, Marsilio, 1997, p. 65.
} 
de los modos más apropiados de tratar una dificultad sin incurrir en daños y peligros que comportaría un experimento real" ${ }^{18}$.

El juego elabora una representación de la realidad, obliga a su simbolización, y haciendo esto, cumple con aquella acción exquisitamente intelectual y cognitiva que es la generacion de imágenes mentales, mapas cognitivos, rutas de significación de lo real. Impone una suerte de mentalización de los procesos implicados enla acción, elabora instrumentos de lectura y de orientación en el mundo, explora roles y socializaciones. Se trata de elementos relevantes para la educación y el conocimiento; por esto sostenemos que lo lúdico expresa una fuerte tensión formativa.Y así, si con la narración y el juego se elaboran imágenes del mundo y de nuestra presencia en él, tales imágenes desarrollan la función de interpretación del mundo mismo y de nuestra presencia, de nuestro hacer y de sus itinerarios. En breve, de nuestro sentido existencial. Tales imágenes elaboran de hecho una suerte de geografía, elaboran instrumentos de orientación, señalan puntos de referencia, posibles rutas existenciales, evoluciones, trans-formaciones.

Aquí está, a nuestro parecer, la función formativa de lo lúdico, es decir, en precisar y construir claves de lectura del mundo; dicho en otros términos: construir conocimiento, problematizar nuestra experiencia intelectual, afinar nuestra sensibilidad. El jugar implica utilizar creativamente símbolos, relaciones de significado que los mismos símbolos pueden buscar. Estas operaciones son muy importantes desde el punto de vista cognitivo y tienen mucho que ver con la posibilidad de generar el imaginario, y más ampliamente, con la educación. Es aquí donde las palabras de Marco Dallari nos parecen emblemáticas: “La narración, como práctica educativa, es lo que tiene de vivo, no sólo en el contexto educativo, sino también en lo vivido por el educador, el sentido del juego por todo lo que se está haciendo, y permite dar al niño no sólo un conocimiento por decir así “científico" de lo que queremos transmitir, sino también cargada de valencia estética” 19.

El juego es acción gratuita, libre de perseguir metas directas y en este sentido es libre, aunque tenga reglas rigurosas. Es libre porque puede desprenderse de la realidad y

\footnotetext{
${ }^{18}$ P. Santagostino, Guarire con una fiaba, Milano, Feltrinelli, 2010, p. 10.

${ }^{19}$ M. Dallari,Gioco, scienza, narrazione, en M. Flavi y A. Francucci, II Mago Sbaffione e altre meraviglie. La narrazione trasversale tra linguaggio, pensiero logico, corpo e ambiente, Firenze, La Nuova Italia, 1989, p.28.
} 
responde sólo al deseo propio de jugar sin aceptar imposiciones. Y es justamente la libertad la condición necesaria de la ética y el sentido profundo de la naturaleza humana, como nos ilustra Michel Foucault en su bellísimo texto sobre el sueño ${ }^{20}$.

La narrativa y sobre todo las fábulas, los mitos y la literatura fantástica, contienen elementos que podremos definir oníricos tanto en el sentido del sueño a ojos abiertos, como en el sueño que actúa durante el sueño. Volviendo a los procesos de la hermenéutica aplicada y al papel desestructurante del logos narrativo, la dimensión onírica es formativa también porque se atiene a lo específicamente humano.

Quien tiene familiaridad con la literatura, aún los niños que escuchan fábulas, sabe que tiene que ver con símbolos y que la realidad habla un diferente lenguaje. Y es ahí que, a niveles muy elementales, da inicio la primera operación de diferenciación entre la percepción de la realidad y la percepción de su representación. Las transformaciones fantásticas, las magias, los encantamientos participan de este juego complejo, pero se trata de un procedimiento que tiene mucho que ver con lo onírico, y es por esto que el niño lo reconoce, no obstante que esté lejos de su realidad cotidiana. Si en el mundo real percibimos un cierto orden que definimos como "racional", en el onírico reina el caos y ahí el sujeto puede experimentar el máximo de libertad: la libertad del logos. Y es también aquí que el imaginario toma buena parte de su material.

Para estudiar el imaginario, debemos familiarizarnos con una sintaxis de tipo onírico, una gramática organizada sobre awonancias, contiguidad, alusiones más que sobre causalidad y cronología. Y es el deseo que liga al sueño con el pensamiento y que provoca el placer gratuito de la fantasía y de la creatividad. El desear da forma a la

\footnotetext{
${ }^{20} \mathrm{Cfr}$. M. Foucault, Il sogno, Milano, Raffaello Cortina, 2003; tit. orig. Introduction in L. Binswanger, Le reve et l'existence" (1954), tomado de Dits et écrits, Paris, éditions Gallimard, 1994. Se trata de una Introducción a la traducción francesa de Sogno ed Esistenza (1930), breve ensayo del psiquiatra suizo Ludwig Binswanger. Aquí el filósofo francés aprovecha la ocasión para desarrollar una rigurosa crítica a los métodos de abstracción y de reducción tanto del psicoanálisis como de la fenomenología. De acuerdo a su investigación, ambas disciplinas tienden a reafirmar el dominio de la conciencia sobre el sentido profundo de lo onírico, privándolo de su consistencia ontológica. Tanto Foucault como Binswanger se alzan contra este reduccionismo, reconociendo, en el sueño, la auténtica manifestación de la existencia. El filósofo nos advierte que no es su intención hacer una exégesis del ensayo de Binswanger, sino que aprovecha la ocasión para "desentrañar un sentido objetivo" (p.25) y recoger la contribución que tal sentido puede ofrecer "a una antropología de la imaginación" (p.53).
} 
indeterminación del sujeto que, hoy, es el adorno de su liquidez ${ }^{21}$. En el sueño Foucault ubica a la experiencia primigenia en la cual el sujeto experimenta, con la libertad del logos, su naturaleza más verdadera.

Con Foucault el sujeto se autodetermina en la conquista de una libertad que el filosofo llama “local”, en tanto que es ajena a toda veleidad política. La imaginación es un lugar donde es posible explorar esta posibilidad, es un fundamento ontológico de la aventura humana, ambiente en el que se realiza una parte importante de su humanidad. Espacio en el que la existencia se anuncia. Es el ámbito educativo por excelencia y añadimos nosotros- laboratorio para cuidar del yo, teatro en el que se representa la experiencia estética. ¿Qué es el sueño? El "movimiento original de la libertad, es nacimiento del mundo en el mismo movimiento de la existencia” ${ }^{22}$. Por este motivo la experiencia onírica no puede ser separada de su contenido ético. El sueño es el lugar de la libre manifestación de la existencia, aquí “es la existencia misma la que, en la direción fundamental de la imaginación, indica su mismo fundamento ontológico" ${ }^{23}$. He ahí que lo onírico no es más solamente una forma de la imaginación, sino su irreductible necesidad.

Si la imaginación está en el origen de una ontología de lo humano, el sueño, para el filósofo francés, es la primera condición de la imaginación, su estructura primitiva. De esa manera lo onírico adopta un papel central en la hermenéutica de la aventura existencial, porque ahí hay una enorme posibilidad de que suenen todas las cuerdas de la libertad. El poder del sueño en esta ocasión concreta consiste en el descubrimiento de la ética. De hecho, la experiencia onírica sanciona el nexo ontológico entre la libertad de la existencia y la necesidad de la presencia en el mundo, porque supera, en otros ámbitos de significación, las categorías de la objetividad. Más aún, soñar es un pensamiento alternativo: es logos estético. El mensaje y la invitación foucaultiana consiste en "reconocer un pensamiento que ofrece más de cuanto dice" ${ }^{24}$. Porque el decir mantiene vigilantes a las normas del conocimiento, el trascender tales leyes significa, por el contrario, entrar en el reino de lo imaginario. Aquí las imágenes mentales se anuncian en

\footnotetext{
${ }^{21}$ Es evidente la cita a los numerosos volúmenes que Zigmut Bauman dedica al tema de la liquidez.

${ }^{22}$ M. Foucault, Il sogno, cit. p. 44.

${ }^{23}$ Idem, p. 75.

${ }^{24}$ Idem, p. 7.
} 
su hacerse, aún indeterminadas en el limbo de las infinitas posibilidades, en la más amplia libertad que el individuo pueda experimentar. La imagen no es todavía "mundo" porque está en estado embrionario, pero al mismo tiempo nos muestra que el mundo no está constituido principalmente de referencias objetivas. El mundo puede ser también el ámbito original de una libertad que se desenvuelve: "el sueño es el mundo aural en su primera explosión, cuando es todavía la existencia misma y todavía no es el universo de la objetividad" 25 . Lo que llamamos "mundo", nos advierte Foucault, es la cosmogonía de nuestra existencia ${ }^{26}$ : la completa narración de nuestra existencia "en el" mundo, de nuestra llegada y nuestra partida, en fin, del sentido que todo esto reviste a nuestros ojos. En breve, es un resumen argumentado de nuestra conciencia según las categorías del logos: “El sueño en su trascendencia, y por su trascendencia, descubre el movimiento original con el cual la existencia, en su irreductible soledad, se proyecta hacia el mundo que se constituye como el lugar de su historia. El sueño revela, en su origen, esta ambiguidad del mundo que todo junto designa la existencia que se poyecta en él y se ofrece a su experiencia en forma de objetividad. Rompiendo con esta objetividad que encanta a la conciencia vigilante, restituyendo al sujeto humano su libertad radical, el sueño revela paradójicamente el movimiento de la libertd hacia el mundo, el punto original a partir del cual la libertad se hace mundo" ${ }^{27}$. Lo onírico nos muestra al mundo en el que la libertad se constituye y se aliena, en el que deviene responsabilidad frente al mundo o se abandona a la causalidad. Lo onírico es “el corazón puesto al desnudo" 28 , “libera el origen, la realización del yo" ${ }^{29}$, el despertar de la existencia.

La objetividad de la que habla el filósofo francés es la forma de la racionalidad con la cual la conciencia vigilante lee e interpreta lo real, o bien: con la que "habla". Pero, nos advierte Foucault, la realidad es también otra cosa: es también sueño, porque en el sueño se manifiesta nuestra existencia primigenia, auténtica, privada de cualquier oropel. Y se manifiesta “libre”. Así, el lenguaje del sueño trasciende las categorías de aquella racionalidad porque sus imágenes todavía no están enjauladas; aún no son “formas

\footnotetext{
${ }^{25}$ Idem, pp. 60/61

${ }^{26}$ Idem, p. 81.

${ }^{27}$ Idem. p. 43.

${ }^{28}$ Idem, p. 45.

${ }^{29}$ Idem, p. 48.
} 
cristalizadas". Aquí, el individuo experimenta libremente su relación con el mundo a través de una estrategia hermenéutica que le muestra el sentido último de su existencia, que es justamente la libertad y que anuncia a la ética. Por esta razón la experiencia onírica es fundamental para interpretar lo humano, toda vez que descubre su libertad original. Esta epistemología del sueño, para Foucault, nos enseña a "mirarse a sí mismo como sentido absoluto del mundo propio, verse como movimiento de una libertad que se hace mundo y al final se establece en él, como destino propio" ${ }^{30}$. El filósofo francés, en su reflexión sobre las dinámicas de lo onírico, nos ilumina sobre las extraordinarias tensiones educativas del imaginario. La conciencia, de hecho, en el acto de imaginar, puede captar el movimiento original que el mismo sueño expresa. Nos puede ayudar a explorarnos, a interpretar nuestro onírico como parte original de nuestra existencia. Es "percibir" que "percibimos", diría Whitehead ${ }^{31}$.

Foucault nos invita a imaginarnos dentro de nuestro sueño: a soñarnos soñantes, a descubrir la presencia de una libertad que ahí se manifiesta como acontecimiento radical. Nos invita a buscar el sentido original de la realidad: "la imaginación en su verdadera y propia función poética relexiona sobre la "identidad". Sondea lo profundo del ser, desacomoda todas las imágenes y crea otras nuevas, porque no llega jamás a la totalidad de la expresión: "dice más de lo que dice”. De hecho, "durante el sueño la actividad en la imaginación se vuelve contra el primer momento de la existencia en el que se realiza la constitución originaria del mundo. Ahora, cuando la conciencia vigilante, al interior de este mundo constituido, pretende apropiarse de tal movimiento, lo interpreta en términos de percepción" 32 .

Aquí el sujeto se muestra despojado de su hábito lógico -un vestido que lo marca en su proceso de determinación - y experimenta, libre y frágil al mismo tiempo, una especie de caos original donde esán abiertas todas las posibilidades. Experimenta la verdad desnuda e individual de la experiencia existencial. Y es aquí, en nuestra opinión, que la aventura educativa puede abrirse a nuevos horizontes de sentido del mundo, a

\footnotetext{
${ }^{30}$ Idem, p. 81.

${ }^{31}$ Cfr. F. Sancén Contreras, La realidad en proceso de ser real, Universidad Autonoma Metropolitana, Mexico, 2003.

${ }^{32}$ M. Foucault, Il sogno, cit., p. 89.
} 
diferentes rutas de significado, a nuevas poiesis, nuevas hermenéuticas y reestablecer sus estructuras eidéticas. La libertad del logos, que el filósofo francés proclama, es la puerta abierta a nuevas exploraciónes del individuo y nuevas hipótesis educativas, a nuevas claves de lectura, a nuevos nexos epistémicos.

\section{Conclusión}

Para que la narrativa exprese plenamente todo su potencial educativo es necesario que los niños sientan de inmediato numerosas impresiones. Por eso es importante que el adulto les narre fábulas y cuentos y que los lea interpretándolos, recitando, modulando el tono de la voz, y acompañándolos con gestos. La ambigüedad del lenguaje narrativo, entre lo onírico y lo lúdico, surge de la semántica de los términos, los límites de las palabras, y por tanto los significados de lo real. Pero, por otra parte, lo típico de los personajes y situaciones, sobre todo de las fábulas, de los mitos y de la literatura infantil, aclara los conflictos que la realidad nos impone en su procesualidad.

En suma, creemos que la educación y su teoría no deben consumir su potencial creativo en prescripciones, recetas didácticas, o modelos. Pensamos en la formación como dimensión narrativa, y en el arte de la educación como tensión lírica que lleva la mirada hacia la belleza, que afina la sensibilidad, que tiende a la cualidad de las relaciones. Si la mentalidad infantil no tiene una capacidad tan amplia para la abstracción como la adulta, es verdadero también que puede perfectamente elaborar rutas de significado, asociaciones para imágenes que utilizará para construir mapas cognitivos del saber. La narración, por tanto, es apta para la fruición infantil porque utiliza símbolos en forma de imágenes y, como dijimos, involucra toda la personalidad del lector-escucha. Así, el niño suple su dificultad de abstracción con el conocimiento estético. Aquí el imaginario amplía su potencial creativo porque puede liberarse de la prisión de la lógica. Los acontecimientos siguen otras rutas, lo onírico irrumpe al descubrir los escenarios y además el conflicto, casi mágicamente, cambia su dirección. Esto sucede más que en otras partes porque la producción imaginativa está ineludiblemente ligada a la emotividad. La vertiente estética de la educación es narración que trae consigo una razón 
poética. Pero ésta es, en nuestra opinión, la finalidad última de una pedagogía que se torna interpretativa, y profundiza su semántica, su éthos.

Si la educación debe ayudar a la persona a problematizar el mundo, a elaborar su geografía con los instrumentos de orientación y decodificación que son ayuda para encontrar su camino, ella no puede dejar de enfrentar, con lo nuevo y lo imprevisto, lo extraordinario y lo maravilloso. La educación debe poder cultivar un pensamiento narrativo. La enseñanza de la literatura y de la escritura debería iniciar con el placer que la narración enciende, se debería asumir el sentido lúdico y proponer estilos cognitivos que no sean unívocos. A este propósito escribe Gianni Rodari: "El encuentro decisivo entre niños y libros se da en los bancos de la escuela. Se da en una situación creativa, donde cuenta la vida y no el ejercicio, ahí podrá surgir aquel gusto por la lectura con el que no se nace, porque no es un instinto. Si se da en una situación burocrática, si el libro viene mortificado como instrumento de ejercicios (copias, resúmenes, análisis gramaticales, etc.), sofocado por el mecanismo tradicional: “interrogación-juicio”, podrá nacer la técnica de la lectura, pero jamás el gusto. Los niños sabrán leer, pero leerán sólo si son obligados" 33 . Esta educación estética tiene un signo diferente porque sugiere construir narraciones que encuetren, en lo particular estudiado, el estilo, la cifra de identificación, el códice aludido, y al mismo tiempo la amplitud de los problemas y, en fin, la complejidad de nuestro tiempo. Pero, ¿cuál es el papel de la Pedagogía narrativa en la escuela? Este horizonte epistemológico y didáctico privilegia el comprender frente al explicar, porque se dirige a describir, interpretar, presentir, estudiar. Permite excursiones heurísticas, itinerarios cognitivos, disidencias y narraciones formativas que, mientras atraviesan los terrenos del humanismo científico contemporáneo, marcan la peculiaridad fenoménica y lo específicamente disciplinario de cada materia de enseñanza.

${ }^{33}$ G. Rodari, Grammatica della fantasia, Torino, Einaudi, 1973, p. 152. 


\section{Bibliografía esencial}

Aa. Vv., L'esperienza emotiva nel processo di insegnamento e di apprendimento, Napoli, Liguori, 1987.

Almeida Ivan., L'intelligibilità narrativa (homenaje a J.L. Borges), en M. Di Fazio (coord.), Narrare percorsi possibili, Longo, Ravenna 1989.

Bachelard Gaston., Il diritto di sognare. Edizioni Dedalo, Bari, 1987.

Bachelard Gaston., La poetica della rêverie, Edizioni Dedalo, Bari, 1972.

Barbieri Gaston. L., Tra testo e inconscio. Strategie della parola nella costruzione dell'identità, FrancoAngeli, Milano, 2007.

Barthes Roland., Introduzione all'analisi strutturale dei racconti, en AA.V., L'analisi del racconto, Bompiani, Milano 1969.

Bateson Gregory., Una teoria del gioco e della fantasia, en Id. Verso un'ecologia della mente, Milano, Adelphi, 1976.

Bateson Gregory., Verso un'ecologia della mente, Milano, Adelphi, 1976.

Bediers Joseph, Les Fabliiaux, Paris, 1983.

Benoist, Luc., Segni, simboli, miti, Milano, Garzanti, 1976.

Bernardi Milena, Il cassetto segreto. Letteratura per l'infanzia e Romanzo di Formazione, Unicopli, Milano, 2011.

Bernardi Milena, Infanzia e Fiaba, BUP, Bologna, 2007.

Bernardi Milena, Infanzia e Metafore Letterarie, BUP, Bologna, 2009.

Beseghi Emy, Grilli G. (Coord.), La letteratura invisibile, Carocci, Roma, 2011.

Bettelheim Bruno, II mondo incantato, Milano Feltrinelli, 1977.

Bianchi Anna Maria, Alla scoperta di ali e radici. Narrazioni di cittadinanza attiva.

Metodologia Pedagogia dei Genitori. Handicap \& Scuola, Anno XXVII, 162: 13-14, 2012.

Biffi Elisabetta (Coord.), Educatori di storie. L'intervento educativo fra narrazione, storia di vita, autobiografia, FrancoAngeli, Milano, 2010.

Biffi Elisabetta, Scritture adolescenti. Esperienze di scrittura nella scuola secondaria, Erickson, Trento, 2010.

Bosi Alessandro (Coord.), Identità e narrazione, Milano, Unicopli, 2003.

Bosi Alessandro, Lo scrittore è la scimmia dell' uomo, en Il cacciatore di silenzi, Chiarini P. (Coord.), Roma, Istituto Italiano di Studi Germanici, Edizioni dell' Istituto, 1998.

Bosi Alessandro, Sociologia dell' educazione e racconto, in Adultità, n. 7, 1998.

Bosi Alessandro., Inseguire, presupporre e velare gli indizi narrativi, en Adultità, n. 19, 2004.

Bouchner Artur, Ellis Carolyn, Ethnografically speaking: autoetnography, litterature and aesthetics, Altamira Press, Walnut Creek, 2002. 
Bruner Jerom, (Coord.), Il gioco (1976), Roma, Armando, 1981.

Bruner Jerom, La cultura dell'educazione. Nuovi orizzonti per scuola, Milano, Feltrinelli, 1997.

Bruner Jerom, La mente a più dimensioni, trad. it., Bari, Laterza, 1988.

Bruner Jerom, La costruzione narrativa della "realtà" en Ammanniti Massimo, Stern Daniel Norman, (a cura di), Rappresentazioni e narrazioni, Bari, Laterza, 1991.

Clandinin Dean Jean, Connelly Michael, Narrative Inquiry. Experience and Story in Qualitative Research, San Francisco, Jossey Bass, 2000;

Demetrio Duccio, (Coord.), Educare è narrare. Le teorie, le pratiche, la cura, Mimesis, Milano, 2012; Poggio P., Mi racconti una storia? Il metodo narrativo nelle scienze sociali, Carocci, Roma, 2004.

Denzin Norman, Lincoln Yvonna, Collecting and Interpreting Qualitative Materials, London, Sage, 1998.

Detti Ermanno, Il piacere di leggere, Firenze, La Nuova Italia, 1987.

Durand Gilbert, Le strutture antropologiche dell'immaginario, Bari, Dedalo, 1972.

Escolano Benito A., La memoria y el deseo. Cultura de la escuela y educacion deseada, Valencia, Tirant lo Blanch, 2002.

Ferraris Maurizio, Conoscenza estetica, in Nicla Vassallo, Filosofia delle conoscenze, Codice Edizioni, Torino 2006.

Fink Eugen, Oasi della gioia, Salerno, Dieci diciasettesimi, 1987.

Fonzi Ada, Elena Negro Sancipriano, Il mondo magico nel bambino, Torino, Einaudi, 1979.

Foucault Michel, Il sogno, Milano, Raffaello Cortina, 2003.

Fraiberg Selma, Gli anni magici, Roma, Armando, 1970.

Gagliardi Mafra, Le stelle nascoste. Mappa del desiderio nell'immaginario infantile, Venezia, Marsiglio, 1997.

Gardner Howard, Formae mentis, Milano, Feltrinelli, 1987.

Goleman Daniel, Intelligenza emotiva, Milano, Rizzoli, 1996.

Gramigna Anita, Righetti Marco, Rosa Carlo, Estetica della formazione. La conoscenza nella bellezza, UNICOPLI, Milano, 2007.

Hegel Georg Wilhelm Friedrich, Estetica, editado por N. Merker, Torino, Einaudi, 1997.

Heidegger Martin, “L'origine dell'opera d'arte”, en Sentieri interrotti, tr. it. editado por P. Chiodi, Firenze, La Nuova Italia, 1968.

Huizinga Johan, Homo ludens, Haarlem, Tjeenk Willink, 1938.

Janer Manila Gabriel, Literatura infantil y experiencia cognitiva. Barcelona: Pirene, 1995. Janer Manila Gabriel, Literatura oral y ecología del imaginario. Madrid: Fundación Germán Sánchez Ruipérez, 2009. 
Janer Manila Gabriel, Pedagogia de la imaginació poètica. Barcelona: Fundació Serveis de Cultura Popular: Alta Fulla, 1986.

Jedlowsky Pablo, Storie comuni. La narrazione nella vita quotidiana, Mondadori, Milano, 2000.

Kaneklin Cesare, Scaratti Giuseppe, (Coord), Formazione e narrazione, Milano, Cortina, 1998.

Kock Kenneth, Desideri, sogni, bugie, Milano, Emme Edizioni, 1970.

Kruglanski Arie, Lay epistemics and human knowledge, NY, Plenum, 1989.

Lieblich Amia, Mashiach Rivka Tuval, Zilber Tamar, Narrative Research. Reading, Analysis and Interpretation, London, Sage, 1998.

Lincoln Y. S. \& Guba E. G., Naturalistic Inquiry, Sage, Beverly Hills, CA, 1985.

Lucignani Giovanni, Pinotti Aandrea, (Coord.), Immagini della mente. Neuroscienze, arte, filosofia, Milano, Cortina, 2007.

Lyotard Jean Francois., La condition postmoderne, Paris, Les Editions de Minuit, 1979.

Malle, Bertram \& Knobe, Joshua, The folk concept of intentionality, Journal of

Experimental Social Psychology, 33, 101-121, 1997.

Mantegazza Raffaele, (Coord.), Per una pedagogia narrativa, Bologna, EMI, 1996.

Mottana Paolo, Formazione e affetti, Roma, Armando, 1993.

Pinotti Andrea, Estetica ed empatia, Milano, Guerrini e Associati, 1997.

Piromallo Gambardella Agata, Pedagogia fra ragione e immaginazione: riflessioni sul pensiero di G. Bachelard, Napoli, Liguori, 1983.

Propp, Vladimir Jakovlevic, Le radici storiche dei racconti di fate, Torino, Boringhieri, 1985.

Propp, Vladimir Jakovlevic, Morfologia della fiaba, Milano, Newton Compton, 1985.

Quaglia Sergio, Pratiche di scrittura nei servizi sociali, Unicopli, Milano, 2010.

Quaia Luciana, Intime erranze. II familiare curante. L' Alzheimer, la resilienza autobiografica, ed Nodo Libri, Como, 2012.

Ricoeur Paul, Dal testo all'azione, Milano Jaca Book, 1989.

Ricoeur Paul, Il conflitto delle interpretazioni, Milano, Jaca Book, 1997.

Rodari Gianni, Grammatica della fantasia, Torino, Einaudi, 1973.

Santagostino Paola, Come raccontare una fiaba ... e inventarne cento altre, Como, Red Edizioni, 1997.

Schön Donald, (1991), The Reflective Turn. Case Studies in and on Educational Practice, Teachers College Press, New York; Smorti A., Narrazioni. Cultura, memorie, formazione del sé, Giunti, Firenze, 2007.

Smorti Andrea (Coord.), Il sé come testo, Firenze, Giunti, 1997.

Smorti Andrea, Il pensiero narrativo, Firenze, Giunti, 1994. 
Valleriani Antonio, Il viandante e la sua strada. Uno sguardo ermeneutico all'orizzonte estetico, Colledara (Te), Andromeda, 1997.

Zambrano Maria, Verso un sapere dell'anima, Milano, Cortina, 1994.

Recebido em: 03/02/2014 Aprovado em: 25/05/2014

Universidade do Estado de Santa Catarina - UDESC Programa de Pós-Graduação em Educação - PPGE Revista Linhas

Volume 15 - Número 28 - Ano 2014 revistalinhas@gmail.com 